\title{
Comparison of the Background Radiation Level within Kanchanpur District, Nepal
}

\author{
G. B. Dhami, M. R. Bhatt, J. Khadayat, B. D. Joshi
}

Journal of Nepal Physical Society

Volume 6, Issue 2, December 2020

ISSN: 2392-473X (Print), 2738-9537 (Online)

\section{Editors:}

Dr. Binod Adhikari

Dr. Bhawani Joshi

Dr. Manoj Kumar Yadav

Dr. Krishna Rai

Dr. Rajendra Prasad Adhikari

Mr. Kiran Pudasainee

JNPS, 6 (2), 34-40 (2020)

DOI: http://doi.org/10.3126/jnphyssoc.v6i2.34854

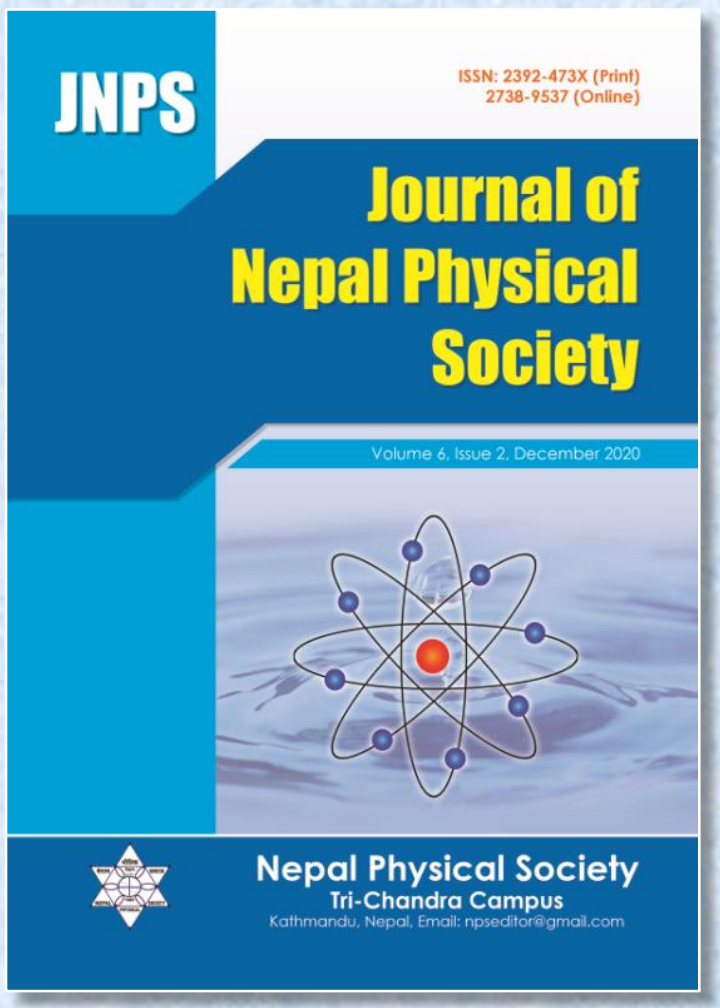




\title{
Comparison of the Background Radiation Level within Kanchanpur District, Nepal
}

\author{
G. B. Dhami ${ }^{1}$, M. R. Bhatt ${ }^{1}$, J. Khadayat ${ }^{1}$, B. D. Joshi ${ }^{1}{ }^{1}$ * \\ ${ }^{1}$ Department of Physics, Siddhanath Science Campus, Tribhuvan University, Nepal \\ "Corresponding Email: bhawani.joshi@snsc.tu.edu.np
}

Received: 23 October, 2020; Revised: 29 November, 2020; Accepted: 27 December, 2020

\begin{abstract}
We have reported the background radiation of urban and some other rural places of Kanchanpur district, Nepal. A simple portable Geiger Muller counter was used to quantify the level of overall background radiation by collecting data of different forty seven (including six urban and forty one rural places) places within the district. Our study reveals that the background radiation level of the study district is below the risk level. The maximum background count values 33.00 \pm 4.47 (Mahakali Zonal Hospital), $33.93 \pm 1.16$ (Mahakali

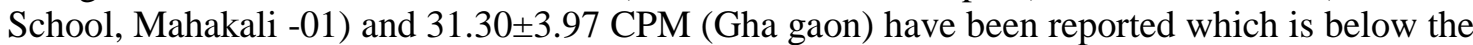
risk level. The observed values of radiation counts at all the sample places indicate that Kanchanpur district is radiation risk free.
\end{abstract}

Keywords: Background count, GM counter, Kanchanpur, Radiation.

\section{INTRODUCTION}

Propagation of energy in the form of waves or particles can be referred as radiation [1-3]. There is radiation everywhere around us. Main sources of the radiation are: cosmic rays (from outer space), radioactive substances on the earth's surface, and our bodies $[4,5]$. The radiating radionuclides found in the environment can be divided into three general categories: primordial (which formed before the earth creation), cosmogenic (which formed as a consequence of cosmic rays interaction) and human produced (which formed due to the human activity). Among these, natural background radiation is the most abundant $[6,7]$. Cosmic radiation is one eminent part of radiation entering into the earth's atmosphere from its surrounding [3]. Alpha, beta, photons and neutrons are most common types of these radiations. Also, the fertilizers are considered as technologically enhanced natural radiation which increases the uranium and partially thorium concentration in environment [8-10]. The radiation exposure situations may include deviations from normal operating procedures including accidents and malicious events [11]. The geological residual processes such as volcanic emissions, earthquakes, global climate change, and geogenic dust exposure such as asbestos and erionite are another sources causing health risk. Many people in developing countries are affected by these health essues which can be prevented or minimized after detailed and comprehensive research and educational outreach programs [12-15].

Literature search reveals that the radiation level of Kanchanpur district, Nepal is not measured yet. Our study aims to record and compare the level of background radiation of different (urban and rural) areas of the district. Some radiation exposure are constant and uniform (cosmic) through the world while the others vary depending upon the local and due to naturally elevated radioactive substances in some local areas. Being deopsits by Chure region originated rivers and improper waste management, we expect some higher radiation at such places. We have measured and compared the levels of background radiation within the study district selecting some urban and rural areas. The radiation levels are recorded little more at the expected areas than the others. The observed level of natural background radiation is not more than 33CPM which shows that the district is safe (below 100 $\mathrm{CPM}$ ) from the radiation. 


\section{MATERIALS AND METHOD}

\section{Study area and data collection}

Kanchanpur, one of the two Terain districts of Sudurpaschim province, Nepal, is surrounded by Dadeldhura district to the north, Kailali to the east and, India to both the west and south at $28.8372^{\circ} \mathrm{N}$, $80.3213^{\circ} \mathrm{E}$ having $1,610 \mathrm{~km}^{2}$ area. There is lower Chure region to the north and Suklafhanta national park (hub of Krishnasar) within the district. A large variation in temparature, about $40-45{ }^{\circ} \mathrm{C}$ during June-July and near abot $10{ }^{\circ} \mathrm{C}$ durin December, takes place within the district. It is internally divided into nine local municipal regions. Out of them Laljhadi and Beldandi are the rural municipalities and rest are the municipalities as shown in Fig. 1. But still there are almost rural areas together with a few urban parts within the district. Some of the rural and urban areas, forty seven places in total, of the Kanpur district has been selected as data collection sites for this study. We have collected data from Sepember 2017 to May 2018.

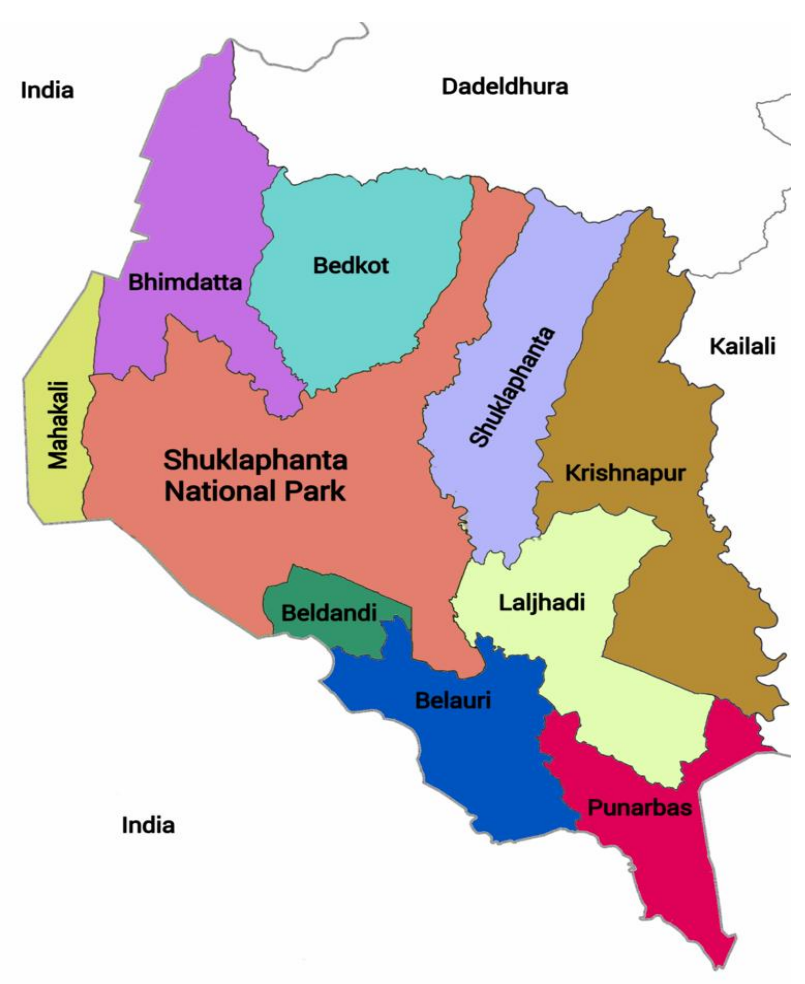

Fig. 1: Map of the study area: Kanchanpur district, Nepal.

A simple portable Geiger Muller (GM) counter has been used for the measurement of the level of background radiation. The direct field observation method was used for data collection purpose. First of all, the working voltage of the instrument used (IEC Geiger counter) was obtained by plotting plateau curve. Then counter was set at the working voltage and data (count readings) were recorded for sixty seconds each. The process was repeated five times each along all the six directions (east, west, north, south, up and down) for all the sample places. At all the places, data were collected at three different times; morning, afternoon and evening, and their corresponding mean values were taken for the analysis. Finally, the average data laverage counts were calculated for individual direction. These data were analyzed using personal computer and spectra have been plotted using origin software.

\section{Geiger Muller Counter}

The IEC Geiger Counter and Rate meter (Model AP 1884-002; size: 195x100x37mm; weight: $0.42 \mathrm{~kg}$; power: $12 \mathrm{~V}$ ) has been used for the data collection as shown in Fig. 2. This fully portable battery operated instrument has been used to count high energy Alpha particles, Beta particles and Gamma rays. This counter has a potential range of 750 volts that can be adjusted and reading range upto four digits with time options 10, 60 and 100 seconds. The counter was kept at $425 \mathrm{~V}$, the operating voltage, and data were collecte for 60 seconds. The GM counter works on the principle of a gas filled detector that consists of a gass 
filled cylindrical tube connected to an applied voltage. When ionizing radiation such as alpha, beta or gamma particles enter into the tube of counter, it ionizes the gas molecule into the tube. The radiation entered into the tube interacts with the gas and create quantifiable charge within few nano seconds. This charge manifests the electric signal that can be measured and referred as the counts.

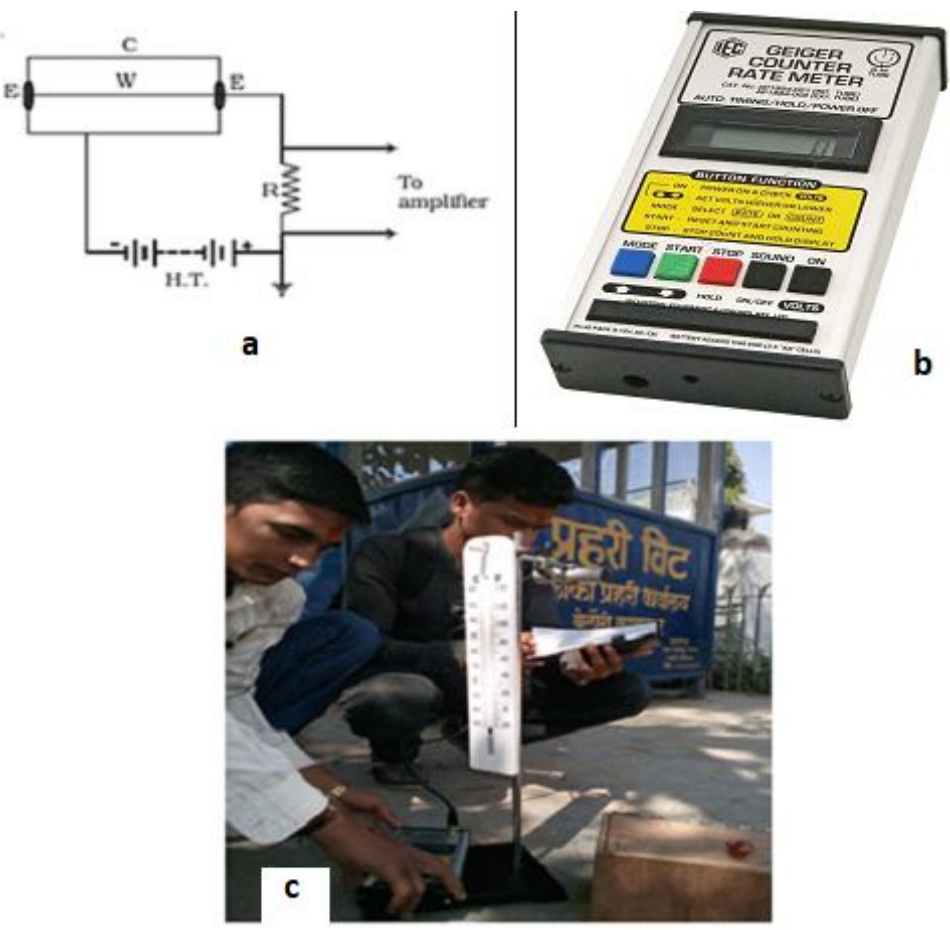

Fig. 2: (a) Internal circuit of G M counter (b) GM counter used for data collection (c) collecting data.

\section{RESULTS AND DISCUSSION}

Using simple GM counter, the level of background radiation of different sample places of Kanchanpur district were recorded in CPM (counts per minute) successfully. The background radiation counts recorded along six different directions have been averaged. The average values with standard deviation of the radiation counts of the corresponding places were calculated and are tabulated as follows:

\section{Background radiation counts of urban areas}

Mahendranagar, Gaddachauki, Jhalari, Brahmdev,
Belauri and International Bank of Reconstruction and Development (IBRD) are main urban (bazar) areas of district. Average background count values of these places and thier standard deviations have been tabulated below in Table 1 .

A bar diagram of the average background radiation counts of different urban places is shown below in Fig. 3. In the Fig. 3, IBRD lying near Dodha river bank, Belauri having brick and sugar factories and, Mahendranagar due to unmanaged waste materials are found to have little higher counts than the other places.

Table 1: Background radiation counts of urban areas of Kanchanpur district with standard deviation and average CPM.

\begin{tabular}{clcc}
\hline S. N. & Name of Urban area & Mean CPM & S. D. \\
\hline 1 & IBRD (Punarbas-03) & 27.2 & 2.70 \\
2 & Belauri (Belauri-05) & 27.65 & 0.65 \\
& Jhalari (Suklaphanta-04) & 24.6 & 1.14 \\
4 & Mahendranagar (Bhimdatt-04) & 26.85 & 0.82 \\
5 & Gaddachauki (Bhimdatt-10) & 23.1 & 2.36 \\
6 & Brahmdev (Bhimdatt-09) & 24.60 & 0.89 \\
\hline
\end{tabular}




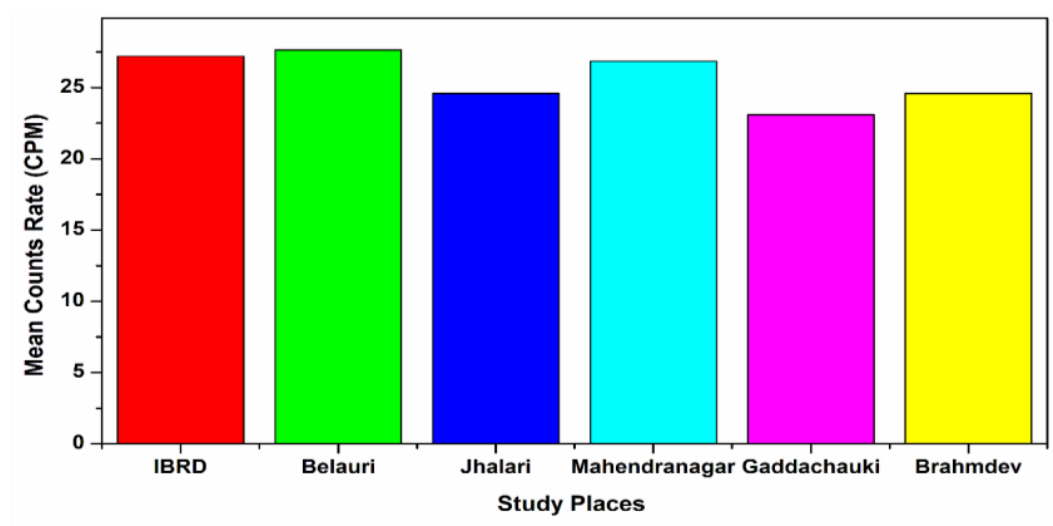

Fig. 3: Bar diagram showing comparison of mean counts of six different urban places.

Similarly, forty one rural areas were selected randomly for the observation procedure. The observed mean background radiation counts for some of these selected rural areas are tabulated below in Table 2 with their their standard deviation values. Among these places, the radiation level at Mahakali Adarsh Secondary school (Mahakali-01) was reported little higher than the other places.

Table 2: Average background radiation counts of some rural areas of Kanchanpur district with standard deviation.

\begin{tabular}{clcc}
\hline S. N. & Name of Rural area & Mean counts (CPM) & S. D. \\
\hline 1 & Bhanu Multiple Campus (Mahakali - 04) & 31.40 & 2.23 \\
2 & Mahakali Adarsh Secondary School (Mahakali-01) & 33.93 & 1.16 \\
3 & Chakkibazar (Mahakali-01) & 31.30 & 4.05 \\
4 & Linga Dhaam (Betkot-05, Bank of Chhela Road) & 28.36 & 4.10 \\
5 & Kalagaudi, Belauri Road (Suklaphanta-12) & 30.24 & 1.77 \\
6 & Puraina (Punarbas-01) & 27.83 & 2.51 \\
7 & Dashrath Basti (Punarbas-04; Near Sugarmill) & 27.53 & 2.25 \\
8 & Gha gaon (Punarbas-05; Near Brick Factroy) & 31.30 & 2.09 \\
9 & Town (Punarbas-06) & 27.26 & 3.59 \\
\hline
\end{tabular}

Comparison of level of background radiation of bazar and some rural areas

The background counts of the bazar (more populated) and their near outreach areas having comparatively low population have been measured.
A graphical comparison of the measured background counts of these populated areas and less populated outreach areas was plotted in a bar diagram is shown in Fig. 4.

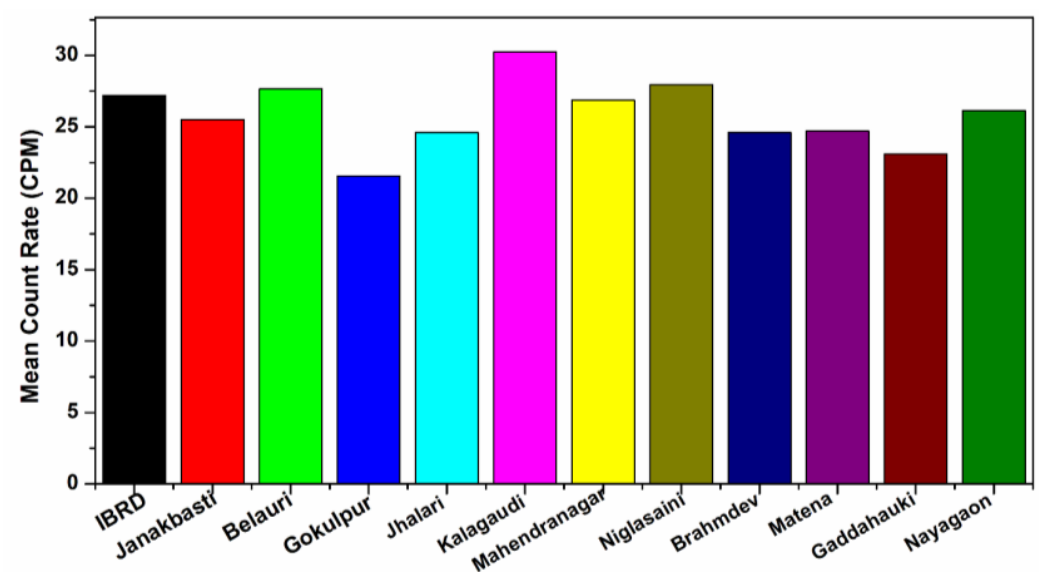

Fig. 4: Bar diagram showing comparison of background counts of urban and some rural places. 

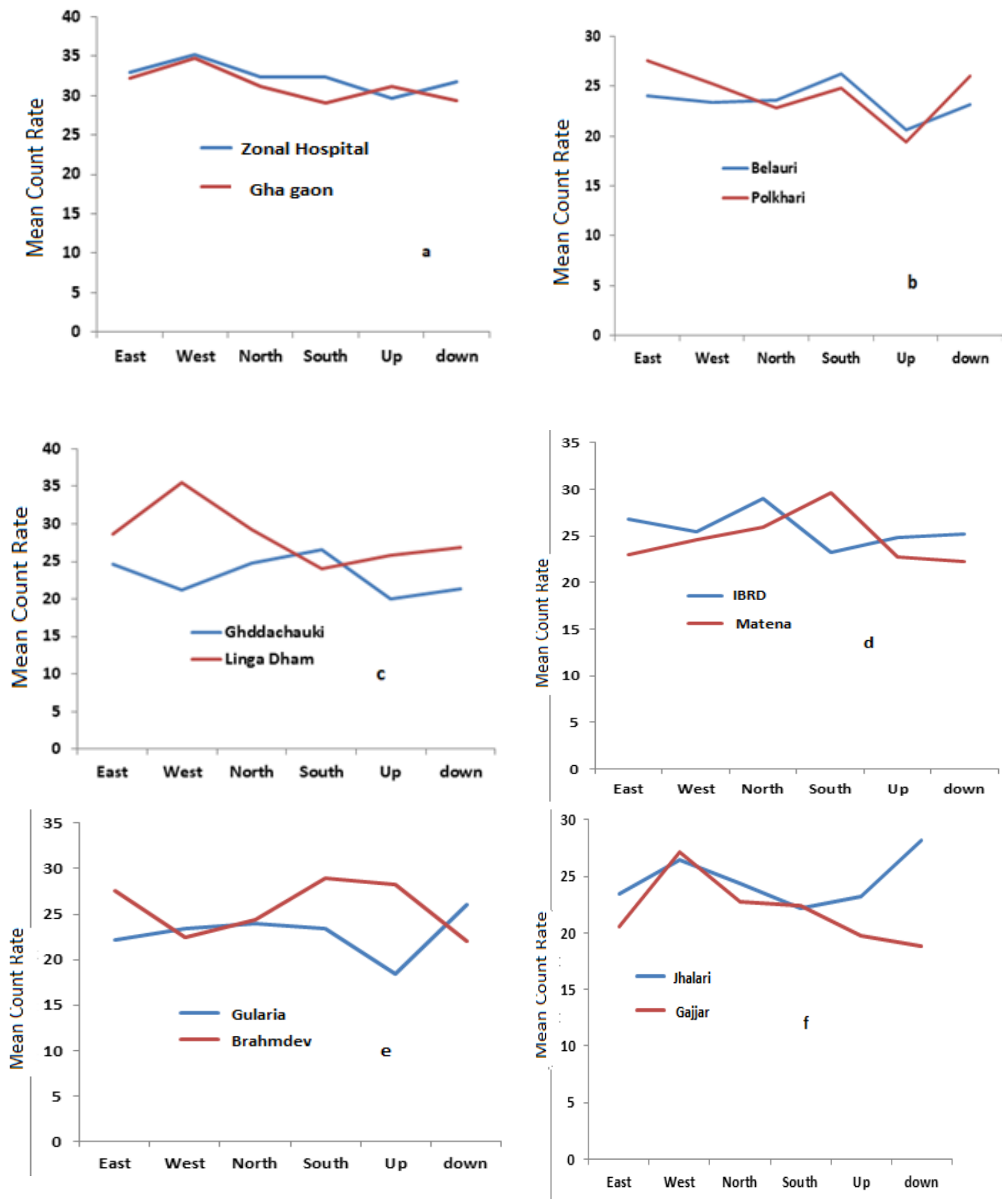

Fig. 5: Mean CPM along different six directions (a) Zonal Hospital and Gha gaon, (b) Belauri and Polkhari, (c) Gaddachauki and Lingha Dham, (d) IBRD and Matena, (e) Gularia and Brahmdev, and (f) Jhalari and Gajjar.

Among these places, the maximum background count was found at Kalagaudi near river bank. This shows that there is the presence of radiating substances in the river bank due to deposited materials through flood from lower Chure regions.
Similarly, the mean counts measured along different six directions near Mahakali Zonal hospital (Bhimdatt-04) and rural Gha gaon (Punarbas - 05), Belauri and Polkhari (Betkot 05), Gaddachauki (Bhimdatt -10) and Linga Dham 
(Betkot-04) and, Matena (Bhimdatt - 09) and IBRD (Punarbas-03) with their standard deviation values are listed below in Table 3. Also, their graphical comparison is shown in Fig. 5. Small variation in count rates at Linga Dham, Brahmdev and Jhalari is due to deposition of clay, mud, soil etc. by the river banks during rainy season from lower Chure belt.

Table 3: Background counts along six different directions of some urban $(*)$ and rural $(* *)$ areas.

\begin{tabular}{|l|l|l|l|l|l|l|}
\hline $\begin{array}{l}\text { Location/ } \\
\text { Direction }\end{array}$ & \multicolumn{1}{|c|}{ East } & \multicolumn{1}{c|}{ West } & \multicolumn{1}{c|}{ North } & \multicolumn{1}{c|}{ South } & \multicolumn{1}{c|}{ Up } & Down \\
\hline IBRD* & $26.80 \pm 4.08$ & $25.41 \pm 1.67$ & $29.00 \pm 4.89$ & $23.20 \pm 3.42$ & $24.80 \pm 3.56$ & $25.20 \pm 4.08$ \\
\hline Matena** & $23.00 \pm 1.22$ & $24.60 \pm 3.20$ & $26.00 \pm 1.00$ & $29.60 \pm 3.84$ & $22.80 \pm 1.92$ & $22.20 \pm 5.44$ \\
\hline Zonal Hospital $*$ & $33.00 \pm 4.47$ & $35.20 \pm 3.42$ & $32.40 \pm 3.20$ & $32.4 \pm 6.60$ & $29.60 \pm 7.50$ & $31.80 \pm 9.03$ \\
\hline Gha gaon** & $32.02 \pm 3.97$ & $34.80 \pm 5.26$ & $31.02 \pm 5.35$ & $29.00 \pm 5.24$ & $31.20 \pm 3.70$ & $29.40 \pm 6.10$ \\
\hline Belauri* & $24.00 \pm 4.52$ & $23.40 \pm 5.42$ & $23.60 \pm 3.91$ & $26.20 \pm 1.64$ & $20.61 \pm 3.36$ & $23.20 \pm 4.60$ \\
\hline Polkhari** & $27.60 \pm 3.43$ & $25.20 \pm 4.96$ & $22.80 \pm 3.03$ & $24.80 \pm 2.40$ & $19.40 \pm 3.04$ & $26.00 \pm 3.53$ \\
\hline Gaddachauki* & $24.60 \pm 3.84$ & $21.2 \pm 4.65$ & $24.8 \pm 7.12$ & $26.6 \pm 4.15$ & $20.00 \pm 7.48$ & $21.40 \pm 4.33$ \\
\hline Linga Dhaam** & $28.60 \pm 4.03$ & $35.50 \pm 3.96$ & $29.20 \pm 5.33$ & $24.00 \pm 3.67$ & $25.80 \pm 2.4$ & $26.80 \pm 4.56$ \\
\hline
\end{tabular}

In this study, the maximum mean background radiation counts were recorded at Belauri (27.65 \pm $0.65 \mathrm{CPM})$ and IBRD bazar $(27.20 \pm 2.70 \mathrm{CPM})$ and, the minimum count was recorded at Gaddachauki $(23.10 \pm 2.36 \mathrm{CPM})$ as urban areas outside from Mahendranagar, the main urbanized city of the study district. It is seen that the average background counts of all the bazar areas are approximately similar. Within Mahendranagar bazar area, the maximum average background count was recorded near Mahakali Zonal Hospital $(32.26 \pm 1.86 \mathrm{CPM})$. It is due to the radionuclides present in medical waste and $\mathrm{X}$-ray exposure from the Hospital. But the background counts were significantly similar at all the morning, day and evening time.

In the case of the rural areas, maximum background counts at Gha gaon (Punarbas-05) near brick factory, Kalagaudi (Suklaphanta -12), Chakki bazar (Mahakali -01), Mahakali Adarsh Secondary School (Mahakali - 01) and at Bhanu Multiple Campus (Mahakali-04) were recorded $31.30 \pm 2.09$, $30.24 \pm 1.77,31.3 \pm 4.05,33.93 \pm 1.16$ and $31.4 \pm$ $2.23 \mathrm{CPM}$ respectively. While the minimum value of $18.01 \pm 5.90 \mathrm{CPM}$ was recorded at Ganeshpur (outreach place near Jhalari bazar) near Janjagritee School (Jungle side). However, at all other rural areas, the recorded values of background counts were approximately similar raging from 2129CPM.

The maximum value of background count at different places of Mahakali Municipality is due to the excess use of chemical fertilizer (containing Nitrogen, Phosporous, Potasium) and some of the high energy radiation from hospitals of Indian bazar areas: Khatima and Banbasa. Also, the higher values of background counts at Kalagaudi and Gha gaun (near brick factory) is due to presence of radioactive isotopes in the soil and/or due to the excess use of chemical fertilizer in agricultural land. In total, the average of mean background count of all the bazar areas is $25.66 \pm 1.80 \mathrm{CPM}$ while that of all the rural areas is $26.11 \pm 3.18 \mathrm{CPM}$ showing no any significant difference between the average background counts of the urban and rural areas. However, comparing individually, some of the rural areas such as: Chakki bazaar, Bhanu Multiple Campus, Kalagaudi, Gha gaun have 5 to 6 more background counts than the other bazar areas. Since, the nornal background radiation count is typically in the range 25 to $75 \mathrm{CPM}$ and the alert level is $100 \mathrm{CPM}$. So, it can be recommended that both the rural and bazar areas of Kanchanpur district having almost similar level of background radiation below risk level are not hazardous for lives. A small difference of $0.45 \pm 1.38 \mathrm{CPM}$ among different rural areas may be due to the vegetation and radioactive soil (due to use of chemical fertilizer).

\section{CONCLUSION}

Present survey was conducted for data collection of the background radiation level of six bazar and foutry one rural areas of Kanchanpur district. 
Comparison of the level of background radiation of bazar and that of rural areas is almost similar i.e. the average of mean of background radiation of six bazar area is $25.66 \pm 1.80 \mathrm{CPM}$ and that of forty one rural areas is $26.11 \pm 3.18 \mathrm{CPM}$. But individually, some of the rural areas are associated with a little bit higher background radiation level than bazar areas and other rural areas. This is due to the geological and geographical conditions like as; land slide and deposition by the rivers. The background radiation counts data were recorded comparativel more near to the agricultural fields in case of the rural areas due to the excess use of chemical fertilizer containing phosphate in agricultural land. The fertilizers are considered as a new category of human radiation exposuer, technologically enhanced natural radiation. The radiation from hospital equipments and their waste materials are another suggested sources leading to the environmental polution. So, from the data record it is concluded that the servey district is below the radiation risk level (refered above 100 CPM). This study has been carried by simple GM counter within shorter time. The measurements by better equipments during longer time period may be further betterment procedure.

\section{ACKNOWLEDGEMENTS}

The authors would like to acknowledge Department of Physics, Siddhanath Science Campus and Mr Ram Nath (official assistant) for providing GM counter for the measurements. We acknowledge Municipalities (Dodhara-Chanani, Bedkot, Suklaphanta, Krishnapur, Belauri and Krishnapur) for providing partial financial support during the period of data collection.

\section{REFERENCES}

[1] Bamidele, L. Measurement of ionizing radiation level in high altitude town of Iimesi IIe, Osun state, south western Nigeria. Environ. Res. J., 7(4-6): 79-82 (2013).

[2] Timilsina, S.; Poudel, K. R. and Poudel, P. R. A study of exposure of overall background radiation in syngja district. Himalayan Phys., 627: 92-95 (2017).

[3] Shahbazi-Gahrouei, D.; Gholami, M. and Setayandeh, S. A review on natural background radiation. Adv. Biomed. Res., 2(3): 1-6 (2013).

[4] Benedick, L. and Jeran, Z. Radiological of natural and mineral drinking water in slovenia. Radiat. Prot. Dosim., 151: 306-313 (2012).
[5] Chetri, R. P. Background radiation: detection, measurement and Hazards. Himalayan Phys., 627: 119-122 (2017).

[6] Giri, K.; Giri, D. and Krishna Murthy, V. Radiation measurement at X-ray centres of a few hospitals in Kathmandu city, Nepal. Kathmandu University J. Sci., Eng. Tech., 1(4): 1-4 (2007).

[7] Geetha, A. C. and Sreedharan, H. Review on studies in high background radian areas (HBRAS) of various parts of the words. Int. J. Adv. Res. Biol. Sci., 3(8): 163-169 (2016).

[8] Ghos, D.; Deb, A.; Bera, S.; Sengupta, R. and Patra, K. K. Measurement of natural radioactivity in chemical fertilizer and agricultural soil, evidence of high level alpha activity. Environ. Geochem. Health, 30(1): 79-86 (2008).

[9] Ramachandran, T. V. Background radiation people and the environment. Iranian J. Radiat. Res., 9: 63-76 (2011).

[10] Kara, U.; Kara, Y. and Akkurt, I. A study on radiation in operating room in suleyman Demirel university. Acta Phys. Pol. A, 130: 401-403 (2016).

[11] ICRP, (Edt, J Velentin), Recommendations of the International Commission on Radiological Protection. ICRP Publication 103, Elsevier, pp 15 (2007)

[12] Centeno, J. A.; Finkelman, R. B. and Selinus, O. Medical Geology: Impacts of the Natural Environment on Public Health, Geosciences, 6(8): 1-3 (2016).

[13] Sivasailanathan, V.; Kumar, P. and Sagadevan, S. Calibration and estimation of efficiency of Geiger Muller counter using a standard radioactive source, Int. J. Phys. Sci., 12(1): 8-12 (2017).

[14] Kanani, K.; Afarideh. H.; Mohammadi, A.; Chai, J. S. and Kim, Y. S. Design, manufacturing and calibration of the new models of silver GM activation counters, Measurement, 153(1): 107300 (2020)

[15] Gesell, T. F. and Prichard, H. M. The Technologically Enhanced Natural Radiation Environment, Health Phys., 28(4): 361-366 (1975). 